\title{
Commentary \\ Recently published papers: a little less ventilation, a little more oxygen please?
}

Jonathan Ball

General Intensive Care Unit, St George's Hospital, London SW17 0QT, UK

Corresponding author: Jonathan Ball, jball@sgul.ac.uk

Published: 27 May 2008

This article is online at http://ccforum.com/content/12/3/152

(c) 2008 BioMed Central Ltd
Critical Care 2008, 12:152 (doi:10.1186/cc6898)

physiology - but these results did not translate into statistically significant outcome improvements, although there was a trend suggesting that a significantly larger trial might produce such an outcome.

The second study, a French multicentre randomised control trial, investigated 767 patients with acute lung injury [2]. The patients were randomised to either a minimal distension strategy (intrinsic plus extrinsic PEEP 5 to $9 \mathrm{cmH}_{2} \mathrm{O}$ ) or a recruitment strategy, in which the PEEP was maximised and plateau pressures were maintained between 28 and $30 \mathrm{cmH}_{2} \mathrm{O}$. A detailed ventilatory protocol including weaning was employed. Patients were recruited, on average, 24 hours after initiation of mechanical ventilation. The recruitment group received significantly higher PEEP and plateau pressures. There was no difference in 28-day or 60-day mortality. There was a significant reduction in ventilator-free days, organ-failure-free days and the need for adjunctive therapies in the recruitment group.

In short, two large studies asking similar questions with significantly different, detailed, protocols reach the same conclusion - that setting a higher PEEP is noninjurious and is possibly beneficial, but only in secondary endpoints. Of note, due to the real-world practicalities of trial recruitment, the majority of patients had received many hours of 'routine' mechanical ventilation prior to study entry, thus potentially missing the vital early effect of any strategy.

Alongside these impressive studies are two editorials that discuss not only these two papers but also the wider problem of how to investigate complex care in the critically ill patient. A series of similar papers and editorials have also appeared over the past few months.

There appears to be a growing consensus that trials, such as the two discussed above, represent a huge amount of work

$\mathrm{BNP}=\mathrm{B}$-type natriuretic peptide; $\mathrm{PEEP}=$ positive end-expiratory pressure. 
but are rarely, if ever, likely to result in clear evidence upon which to base the treatment of an individual patient. For example, if one takes lung-protective ventilation to its logical extreme, then alternative modes of ventilation such as airway pressure release ventilation or high-frequency oscillatory ventilation should provide even greater benefit than a lowtidal-volume high-PEEP strategy, yet they remain principally the province of enthusiasts or are reserved for rescue modalities. Similarly, the use of permissive hypoxaemia and hypercapnia in such patients results in less injurious ventilation strategies, but awaits large-scale investigation. To conclude, despite the very great efforts employed by the investigators of these two studies, there remain more questions than answers.

\section{Accumulating evidence for $\beta_{2}$-agonists in the treatment of all-cause pulmonary oedema}

$\beta_{2}$-agonists have been shown to enhance the clearance of alveolar and interstitial pulmonary oedema in a number of experimental settings. Two recent studies add further evidence to this intervention.

In the first study, 24 patients undergoing elective lung resection, who were preoperatively assessed to be at high risk of postoperative pulmonary oedema, were given nebulised salbutamol and ipratropium at 6-hourly intervals in a randomised order and in a blinded fashion [3]. The oxygenation index, cardiac index, extravascular lung water index and pulmonary vascular permeability index were assessed preoperatively and postoperatively as well as pre and 50 minutes post each nebulised therapy. The extravascular lung water index and pulmonary vascular permeability index both increased postoperatively. Salbutamol, but not ipratropium, induced on average a $20 \%$ reduction in both parameters, together with a sustained improvement in the oxygenation index and cardiac index.

In the second study, a rat model of acute lung injury was used to test the effects of terbutaline instillation versus systemic administration [4]. Radiolabelled proteins were quantified in various body compartments over time to assess the flux across the alveolar epithelium and pulmonary capillary endothelium. In a complex series of experiments involving a variety of injurious ventilation strategies, pulmonary instillation of terbutaline reduced protein flux across both barriers whereas systemic terbutaline only reduced the flux from the circulation into the alveoli - in essence, suggesting that $\beta_{2}$-agonists may be more efficacious when nebulised rather than when administered systemically.

\section{Ventilator-induced diaphragm injury}

In stark contrast to the large acute lung injury trials described above, a small trial has been published investigating the effects of complete diaphragmatic inactivity coupled, of course, with mechanical ventilatory support [5]. The investigators took diaphragm biopsies from 14 brain-dead organ donors and compared them with eight patients having elective thoracic surgery. The former had been ventilated for 18 to 69 hours, and the control group for 2 to 3 hours. Histological assessment of the biopsies revealed dramatic atrophy with evidence of apoptosis.

The study adds significantly to a number of previous small studies suggesting that maintaining at least some spontaneous breathing effort in mechanically patients should be attempted. The diaphragmatic injury caused by mandatory ventilatory modes coupled with the sedation and sometimes neuromuscular blockade required to achieve them may well have been underestimated, to say nothing of the deleterious effects on ventilation and perfusion in the dependent lung. Ventilator-induced diaphragm injury appears to be yet another potentially avoidable, organ-supportive, iatrogenic injury to add to the seemingly ever-growing list.

\section{Weaning and B-type natriuretic peptide}

To round off the respiratory theme, a simple but elegant study has been published that examines the added value of measuring B-type natriuretic peptide (BNP) before and after a spontaneous breathing trial in predicting extubation failure [6]. There has been a plethora of studies assessing the diagnostic value of BNP testing in the patient presenting with dyspnoea, with elevated levels being associated with cardiac dysfunction and, most usefully, with a negative predictive value rather than a positive one. In the critically ill patient, however, BNP is merely a marker of cardiac strain and is universally elevated in hyperdynamic and shocked patients, regardless of the aetiology.

In this study, 41 patients who met a standard set of criteria for extubation were subjected to a 2-hour T-piece trial to assess their suitability. BNP levels were measured just prior to and at the end of the trial. A greater than 20\% increase in BNP levels accurately and reliably predicted extubation failure. This cutoff value was then prospectively tested in a further cohort of 49 patients with almost identical results. With the potential advent of near-patient testing for BNP, this may prove to be a valuable adjunctive assessment to promote both a more successful and possibly a more aggressive approach to liberating patients from mechanical ventilation.

\section{Oxygen, the magic bullet in severe sepsis?}

As I have previously commented in this series of editorials, oxygen - perhaps the first therapy we instigate in critically ill patients - remains poorly understood in terms of both benefit and injury [7]. To highlight this subject, another detailed animal experiment has been published suggesting that hyperoxia has significant beneficial effects as a component of early resuscitation in severe sepsis. Barth and colleagues induced faecal peritonitis in 20 anaesthetised pigs, and randomised one-half to receive just enough oxygen to maintain arterial haemoglobin oxygen saturations $\geq 90 \%$ and the other half to receive $100 \%$ inspired oxygen [8]. The 
animals were very intensively monitored and continuously resuscitated with fluids and vasopressors for 24 hours before being euthanised. The hyperoxic pigs showed no evidence of oxygen toxicity but instead demonstrated attenuated endorgan dysfunction in the lungs, liver and kidney.

Whether an anesthetised pig with continuous and aggressive haemodynamic support represents a good model for the shocked human is debateable, but with the increasing evidence in favour of hyperoxia and very limited data of oxygen toxicity in humans, this simple, cheap and easily available therapy warrants investigation in patients.

\section{Competing interests}

The author declares that they have no competing interests.

\section{References}

1. Meade MO, Cook DJ, Guyatt GH, Slutsky AS, Arabi YM, Cooper DJ, Davies AR, Hand LE, Zhou Q, Thabane L, Austin P, Lapinsky S, Baxter A, Russell J, Skrobik Y, Ronco JJ, Stewart TE, for the Lung Open Ventilation Study I: Ventilation strategy using low tidal volumes, recruitment maneuvers, and high positive endexpiratory pressure for acute lung injury and acute respiratory distress syndrome: a randomized controlled trial. JAMA 2008, 299:637-645.

2. Mercat A, Richard J-CM, Vielle B, Jaber S, Osman D, Diehl J-L, Lefrant J-Y, Prat G, Richecoeur J, Nieszkowska A, Gervais C, Baudot J, Bouadma L, Brochard L, for the Expiratory Pressure Study G: Positive end-expiratory pressure setting in adults with acute lung injury and acute respiratory distress syndrome: a randomized controlled trial. JAMA 2008, 299:646655.

3. Licker M, Tschopp J-M, Robert J, Frey J-G, Diaper J, Ellenberger $\mathrm{C}$ : Aerosolized salbutamol accelerates the resolution of pulmonary edema after lung resection. Chest 2008, 133:845-852.

4. de Prost N, Dreyfuss D, Ricard J-D, Saumon G: Terbutaline lessens protein fluxes across the alveolo-capillary barrier during high-volume ventilation. Intensive Care Medicine 2008, 34:763-770.

5. Levine S, Nguyen T, Taylor N, Friscia ME, Budak MT, Rothenberg P, Zhu J, Sachdeva R, Sonnad S, Kaiser LR, Rubinstein NA, Powers SK, Shrager JB: Rapid disuse atrophy of diaphragm fibers in mechanically ventilated humans. N Engl J Med 2008, 358:1327-1335.

6. Chien JY, Lin MS, Huang YC, Chien YF, Yu CJ, Yang PC: Changes in B-type natriuretic peptide improve weaning outcome predicted by spontaneous breathing trial. Crit Care Med 2008, 36:1421-1426.

7. Ball J: Recently published papers: the Jekyll and Hyde of oxygen, neuromuscular blockade and good vibrations? Crit Care 2007, 11:108.

8. Barth E, Bassi G, Maybauer DM, Simon F, Groger M, Oter S, Speit G, Nguyen CD, Hasel C, Moller P, Wachter U, Vogt JA, Matejovic M, Radermacher P, Calzia E: Effects of ventilation with $100 \%$ oxygen during early hyperdynamic porcine fecal peritonitis. Crit Care Med 2008, 36:495-503. 